\title{
Coronary thrombolytic treatment at home
}

\author{
An aspirin and quick admission to a coronary care unit is probably a better bet
}

People with acute myocardial infarction think twice before calling the doctor. A delay of about two hours is usual for those who are recruited to clinical trials of thrombolytic treatment, but in many European cities delays of three to five hours are not uncommon. Surprisingly, the delay is not influenced by previous experience of cardiac pain, and even cardiologists have waited two days before seeking help, which supports the idea that denial is an important factor. These delays persist despite the widespread publicity that followed the trials of thrombolytic treatment, which showed that early treatment saved lives. Campaigns to educate the public to seek help earlier have only a brief effect and recruit more patients with non-cardiac chest pain. If we cannot persuade patients to seek help earlier what about reducing transport time by taking help to the patient?

The first purpose of coronary care is to relieve pain and anxiety. Analgesia and the presence of trained staff are therefore the first requirements. The second purpose is to resuscitate the victims of cardiac arrest. The importance of appropriately trained medical staff who can administer an opiate and defibrillate the patient must not be forgotten in this era of thrombolysis. Lives continue to be saved in the streets of Belfast, Seattle, Brighton, and wherever prehospital coronary care is established. Heartstart Scotland is the latest such venture, based on the ambulance service and supported by funds from the British Heart Foundation. The experience of these schemes shows that, when a patient's collapse is witnessed and defibrillation performed within six minutes, survival is possible. Overall about one in seven patients leave hospital, not a very encouraging result but worth while given the large numbers at risk and the modest cost of training and equipping an ambulance and crew. ${ }^{1}$

Giving thrombolytic treatment in the home is a logical development of the observation that earlier treatment saves more lives. In the large studies of streptokinase, ${ }^{23}$ anistreplase ${ }^{4}$ and alteplase ${ }^{5}$ most benefit was seen in patients treated within three to four hours after the onset of symptoms. An analysis of those patients treated within one hour in the GISSI (Gruppo Italiano per lo Studio della Streptochinasi nell' Infarcto Miocardico) study suggested a further modest benefit ${ }^{2}$; unexpectedly this was not confirmed in the ISIS 2 study (second international study of infarct survival). ${ }^{3}$ Julian has drawn attention to another anomaly in these trialsnamely, mortality is not substantially higher in those patients seen very early (DG Julian, European Society of Cardiology,
Stockholm, 1990); this is in sharp contrast to the classic studies of the natural course of myocardial infarction in the community. It may be that patients recruited to the thrombolytic trials are in some way atypical. But despite these anomalies our knowledge of the pathology of coronary thrombosis and myocardial infarction indicates that early reperfusion preserves myocardium. We should therefore try to treat our patients as early as possible.

Prehospital thrombolytic treatment is well established in some centres - for example, Jerusalem, where Gotsman and his colleagues regard the benefits as self evident. The European myocardial infarction project is randomising patients to receive anistreplase or placebo, either on the arrival of the mobile coronary care unit at the patient's home or on the patient's arrival at hospital. By September 1990, 2027 patients had been recruited; for those treated at home the time from the onset of symptoms to treatment had shortened to two hours compared with three hours for those treated conventionally. Simoons and his colleagues have shown a shortening of some 47 minutes in their study, using alteplase and a coronary ambulance. Particularly interesting in this study is the electrocardiographic diagnosis of infarction using electrodes incorporated into a plastic vest and computer interpretation of the electrocardiogram with telephone back up if required. Only 188 patients had been treated in the first 7760 calls. From these preliminary and so far unpublished studies the complications have been few. But is this the way to go in Britain?

We are privileged to have a widespread, good general practitioner service. Anistreplase and alteplase may be given quite simply in the home. Both drugs are being indirectly promoted to general practitioners through invitations to workshops and help in setting up a coronary care service in the home. Both drugs are more expensive than streptokinase and neither is clearly superior, as judged by the preliminary results from ISIS-3 which was a direct comparison of streptokinase, anistreplase, and alteplase in a hospital setting. ${ }^{6}$ The Royal College of General Practitioners Manchester research unit is now embarking on a community study of anistreplase in acute myocardial infarction. When the results of this and the other studies of prehospital thrombolysis become available we will then be in a better position to make an informed decision.

Meanwhile, readers would be well advised not to make hasty judgments and to reflect that 25 years ago, when many 
perceive the standard of general practice to have been at a low ebb, the worst advice for a patient with chest pain was reckoned to be "take two aspirins and go to casualty"; nowadays the very best advice is to "take one aspirin and go as fast as possible to the nearest hospital coronary care unit."

Consultant Cardiologist,

M C PETCH

Regional Cardiac Centre, Papworth Hospital,

Cambridge CB3 8RE
1 Rowley JM, Garner C, Hampton JR. The limited potential of special ambulance services in the management of cardiac arrest. Br Heart $\mathcal{F} 1990 ; 64: 309-12$.

2 Gruppo Italiano Per Lo Studio Della Streptochinasi Nell'Infarto Miocardico (GISSI). Effectivenes of intravenous thrombolytic treatment in acute myocardial infarction. Lancet 1986;i:397-402.

3 ISIS-2 Collaborative Group. Randomised trial of intravenous streptokinase, oral aspirin, both, neither among 17,187 cases of suspected acute myocardial infarction: ISIS-2. Lancet 1988;ii:34960.

4 AIMS Trial Study Group. Effect of intravenous APSAC on mortality after acute myocardial infarction: preliminary report of a placebo controlled trial. Lancet $1988 ;$; $: 545-9$.

5 Wilcox RG, von der Lippe G, Olsson CG, Jensen G, Skene AM, Hampton JR. Trial of tissue plasminogen activator for mortality reduction in acute myocardial infarction. Anglo-Scandinavian study of early thrombolysis. Lancet 1988;ii:525-30.

6 O'Donnell M. Battle of the Clotbusters. BMF 1991;302:1259-61.

\section{What determines the age at the menopause?}

\section{The number of ovarian follicles seems the most important factor}

The menstrual discharge ceases in most women about their fortieth year; but with those in whom it goes on longer it lasts even to the fiftieth year, and women of that age have been known to bear children. But beyond that age there is no case on record.

Aristotle's assessment was similar to those of Hippocrates and also Roman authors, so it seems that 2000 years ago most women entered the menopause in their early $40 \mathrm{~s} .{ }^{2}$ Mediaeval authors, however, gave the 50 s as the age when menses ceased $^{3}$ - much closer to the timing for twentieth century women.

In the past 100 years data from schoolchildren have shown a steady fall in the age at menarche in industrialised communities. ${ }^{4}$ Has there been a corresponding change in the age at the menopause? Unfortunately, reported surveys of the menopause have suffered from methodological defects. Retrospective interviews underestimate the age at the menopause, as does digit preference when women round up a recollected age to 40,45 , or 50 years. A mean also underestimates the age at the menopause; it would be more accurate to use the median. Even in prospective studies there is no agreement on whether the menopause begins with the last episode of bleeding or after amenorrhoea has been present for nine months or more.

Nevertheless, those studies least subject to bias show a striking agreement that the median age at the menopause is currently around 50 in Western industrialised societies. ${ }^{5}$ In Britain it is $50 \cdot 78,{ }^{5}$ in the United States $49 \cdot 8,{ }^{6}$ and in white South Africans $48 \cdot 7^{7}$ with little apparent change over the past century. In non-European women, however, the menopause seems to occur earlier - in South Africa and the United States black women have an earlier menopause than white women. ${ }^{89}$

What determines the age at which the menopause occurs? For most of the factors claimed to influence the timing the evidence is poor. For example, the common belief that women with an early menarche have a later menopause or the reverse has no factual basis. ${ }^{5}$ Nutrition, however, is important. In New Guinea a group of women with severe prolonged malnutrition and low height and weight had a median age at the menopause of only 43.6 years whereas another group in the same region but with much better nutrition and correspondingly greater height and weight had a later menopause, at $47 \cdot 3$ years. ${ }^{10}$

Parity is linked with menopausal age: nulliparous women have an early menopause, ${ }^{711}$ while increased parity, particularly in the higher social classes, correlates with a later menopause. ${ }^{512}$ One surprising report is that mothers of twins enter the menopause about a year earlier than women who have had singleton infants ${ }^{12}-$ why is not clear. A woman's age at the time of her last pregnancy has also been reported to influence her age at the menopause, women whose last pregnancy occurred before the age of 28 reputedly having an earlier menopause than those with their last pregnancy at a later age. ${ }^{13}$ This could, however, be due to a longer fertile period in the women with later pregnancies. There is also some evidence that blindness may lead to a later menopause. ${ }^{14 a}$

Chronic systemic infections or localised disease of the reproductive system impair fertility, but neither systemic nor genital disease seems to influence the age at the menopause. With the exception of mumps oophoritis, pelvic or systemic infections rarely cause ovarian failure. A familial link associated with partial deletion of the long arm of the $\mathrm{X}$ chromosome has been found in a few cases but not in our series. ${ }^{14 \mathrm{~b}} 14 \mathrm{c}$

One of the few well documented influences on the age at the menopause is tobacco smoking. Women who smoke enter the menopause up to two years earlier than those who do not. ${ }^{15-18}$ The effect seems to be dose related and may be mediated partly through lowered oestrogen concentrations. ${ }^{19-21}$ Studies in rodents have shown that benzpyrene destroys primordial oocytes. The rodent ovary contains an enzyme system metabolising polycyclic aromatic hydrocarbons to cytotoxic, potentially carcinogenic intermediates. ${ }^{22}$ If the human ovary responds similarly this would explain the earlier menopause of cigarette smokers. The aromatic hydrocarbons of cigarette smoke might also accelerate aging of oocytes by increased oxidation of cell membranes as a result of combustion products such as nitrous oxide. ${ }^{23}$

The most important factor determining a woman's age at the menopause is the number of ovarian follicles. Human primordial germ cells separate from somatic cells at an early stage of embryogenesis. Some $1000-2000$ migrate to the gonadal ridge, where they multiply rapidly to a maximum of between five million and seven million follicles around the fifth month of intrauterine life. Multiplication then stops. Thereafter there is a steady loss of primordial follicles from the fetal ovary, so that by the time the baby is born each ovary contains about one million follicles. ${ }^{24} 25$

This number continues to diminish after birth (independently of any cyclic hormonal change or the physiological state of the woman), but fewer than $0.01 \%$ are ovulated; the remainder degenerate. Little is known about the mechanisms responsible, although the observations that follicles fail to grow in anencephalic fetuses ${ }^{26}$ and that in rodents hypophysectomy retards the rate of loss of primordial follicles ${ }^{27}$ show the importance of the pituitary gland. Depletion of ovarian follicles occurs independently of physiological and environmental factors (with the exception of those that actually destroy follicles) until the perimenopausal phase is reached. The rate of loss of primordial follicles then acce- 